\title{
Sensitive Analysis of Tuned Mass on High Cycle Fatigue Safety Factor of Crankshaft
}

\author{
H. Karimaei $^{1 *}$ \\ 1. Aerospace Research Institute, Ministry of Science, Research and Technology, Tehran, Iran
}

\begin{abstract}
Torsional vibration (TV) is one of the major issues and very important calculation for the safe running of internal combustion engines, specifically crankshaft. The properties of parts connected to the crankshaft have significant effect on vibration of the system as well as the crankshaft life. Initial selection of this part is usually specified based on engine designer experience and also the torsional vibration calculation of the crank train. In this paper, the focus is to find optimum tuned mass to connect to the crankshaft from the damper side using CAE tools. It is a mounting disk at the free end of the crankshaft named tuned mass. Therefore, the effect of tuned mass inertia on design criteria, especially crankshaft life, was investigated. The results show high sensitivity of high cycle fatigue safety factor of crankshaft to tuned mass. Therefore, adding a suitable tuned mass to the system can increase the crankshaft life, when needed. The results were presented in the paper in detail.
\end{abstract}

Keywords: Classical Torsional vibration, Cranktrain, Tuned mass, High cycle fatigue, Crankshaft life.

\section{Nomenclature}

\section{Latin letters}

$\mathrm{Cr} \quad$ Relative damping coefficients between two engine

Crankshaft throws $[\mathrm{Ns} / \mathrm{m}]$

Ca External damping coefficients $[\mathrm{Ns} / \mathrm{m}]$

$i \quad$ Combustion cycles per revolution

I Inertia, Inertia of crankshaft throw [kg.m2]

$K_{t} \quad$ Stiffness, Stiffness of crankshaft throw [N/m]

$n \quad$ Engine speed [rpm]

$T \quad$ Vibratory torque $\backslash$ Torque $[\mathrm{Nm}]$

$V_{h} \quad$ Cylinder volume $[\mathrm{m} 3]$

Greek letters

$\chi \quad$ Loss factor

$\theta \quad$ Twist angle [Rad]

$\omega \quad$ Phase velocity of vibration, $\mathrm{rad} / \mathrm{s}$

$\varphi \quad$ Vibratory angle propeller, rad

\section{Abbreviations}

fmep Friction mean effective pressure [bar]

$n c \quad$ Number of crank throws

\section{Introduction}

Torsional Vibration (TV) is one of the major issues and very important calculation for the safe running of internal combustion, specifically crankshaft. Torsional vibration analysis is a common simulation task in the design process of cranktrain systems in internal combustion engines [1]. The Holzer method has been successfully used in the calculation of torsional vibration for many years ([2], [3] and [4]). There are several codes developed for solving the torsional vibration problem which are validated with experimental results. The

\footnotetext{
* Corresponding Author Emails: karimaei@ari.ac.ir
}

results of three computational codes which had been developed for solving the torsional vibration problem, including Holzer-forced vibration method, TORVAP and TSC have been compared by Chen and Chang [5]. Also a simulation method for the torsional vibration was represented by Hafner and Maass [4], and a torsional vibration solution by Matrix method was presented by Larmi [6]. In these methods, the effects of variable inertia of ICEs were ignored. However, it is shown that the torsional vibration of reciprocating engines cannot be accurately modelled without considering variable inertias.

Some solution methods for the torsional vibration problem based on the Multi-Body Dynamic (MBD) were presented by Boysal and Rahnejat [7]; Ma and Perkins [8]; in which the exact equations of the motion based on the multi-body dynamic, including the variable inertia effect has been considered. Monitoring large engines was done by Desbazeille et al. [9] by analysing the crankshaft angular speed variations. It is focused on a powerful 20-cylinder diesel engine with crankshaft natural frequencies within the operating speed range. Mechanical and combustion parameters of these models were optimised with the help of measurement data.

By Han et al. [10], the root cause analysis of the high torsional vibration which occurred in the actual ship through a parametric study performed using numerical analysis were described. Parameters that can increase the torsional vibration of the propulsion shaft were selected. To find the cause of the malfunctions, a simulation model coupling the speed control system with the torsional vibration of deformable shafting was proposed and investigated by Guo et al. [11]. In the 
coupling model, the shafting was simplified to be a deformable one. The results of instantaneous rotation speed from this proposed model agreed with the test results very well.

In the present paper, two different software have been used to analyse the torsional vibration system. The first one was carried out using $\mathrm{ADAMS}^{\circledR} /$ Engine commercial software, and the second one was carried out by $\mathrm{AVL}^{\circledR} /$ Designer. In $\mathrm{ADAMS}^{\circledR} /$ Engine, the crankshaft is considered as the torsional-flexible part and the solution is carried out based on the Multi-Body Dynamic [12]. The procedure of torsional vibration analysis in $\mathrm{AVL}^{\circledR} /$ Designer software is based on the Holzer-Forced Vibration method [13]. Finally, the results of the both analyses are presented and compared in the following. Optimising the characteristics of torsional vibration elements like tuned mass is key issue in designing a torsional vibration system. In a TV system, there are many elements, but not all of their properties could be changed for different applications such as crankshaft stiffness or the size of the elements. The present paper focuses on the effect of the tuned mass inertia on the whole cranktrain system and, therefore, a detailed torsional vibration solution method is implemented. The effect of tuned mass inertia on the crankshaft life such as high cycle fatigue safety factors (SF) of the crankshaft was studied here that can be used for selection of the optimum tuned mass. This study will help designers to design an optimal torsional vibration system in terms of improving crankshaft life by adding a tuning disk to the torsional damper.

\section{Torsional Vibration Calculation}

Torsional vibration calculation analysis is performed based on the formulation of a torsional vibration model. The engine shafting system is divided in several rigid bodies ( Figure 1), i.e. some masses. The torsional springs connect these masses to each other. The components in this engine cranktrain system are as shown in Figure 1. The engine crankshaft is divided to 7 masses (mass numbers 3 to 9). Mass numbers 4 to 9 corresponds to six crankshaft throws and the mass number 3 corresponds to the crankshaft end shaft and the flange and the tuned mass including the gears and camshaft inertia. Here a new developed turbocharged inline six-cylinder engine has been studied. The rated power of the engine is $700 \mathrm{~kW}$ at $1800 \mathrm{rpm}$. In this paper the torsional system of this engine in the steady power generation application is studied.
The important characteristics of a torsional vibration system including inertia, stiffness and damping coefficient are described as follows:

\section{Inertia}

3D solid model of the crankshaft was drawn using Pro/Engineer. The inertias of the system can be determined by CAD software. The inertia of a single crank throw is calculated by cutting it from the crankshaft model. Engines usually have a gear train for power transmission to the other devices such as water pump, oil pump and camshaft. The inertia of this system is considered in an equivalent model and is added to the inertia of number 3 in Figure 1 . Connecting rods also were considered as two divided mass in $\mathrm{AVL}^{\circledR}$ and in ADAMS ${ }^{\circledR}$ which is simulated by the centre of gravity location, mass and inertia tensor.

\section{Stiffness}

The torsional stiffness of all sections of the crankshaft model can be calculated using the finite element method, such that a constant torque is applied at the one side of the part while the other side is clamped. Then the twist angle is obtained. The relation between the torque and the calculated twist angle is the torsional stiffness considered in the equivalent model. Therefore, the torsional stiffness can be calculated as follows:

$$
K_{t}=\frac{T}{\theta}
$$

More details for such a calculation have been done by Milasinovic et al. [14].

\section{Damping coefficient}

The relative damping coefficient between two engine crankshaft throws, $\mathrm{Cr}$, can be obtained from the loss angle property. The loss factor is 0.06 for small engines up to 0.28 for big engines and could be expressed by the following equation [4]:

$C r(i)=\frac{k t(\mathrm{i}) \cdot \chi}{i . n}$

Also the external damping coefficient, $\mathrm{Ca}$, can be calculated by the following equation [4]:

$C a(i)=\frac{f m e p \cdot V_{h}}{4 \cdot \pi \cdot n \cdot i \cdot n_{c}}$

The damping of the damper is also supplied by its supplier. 


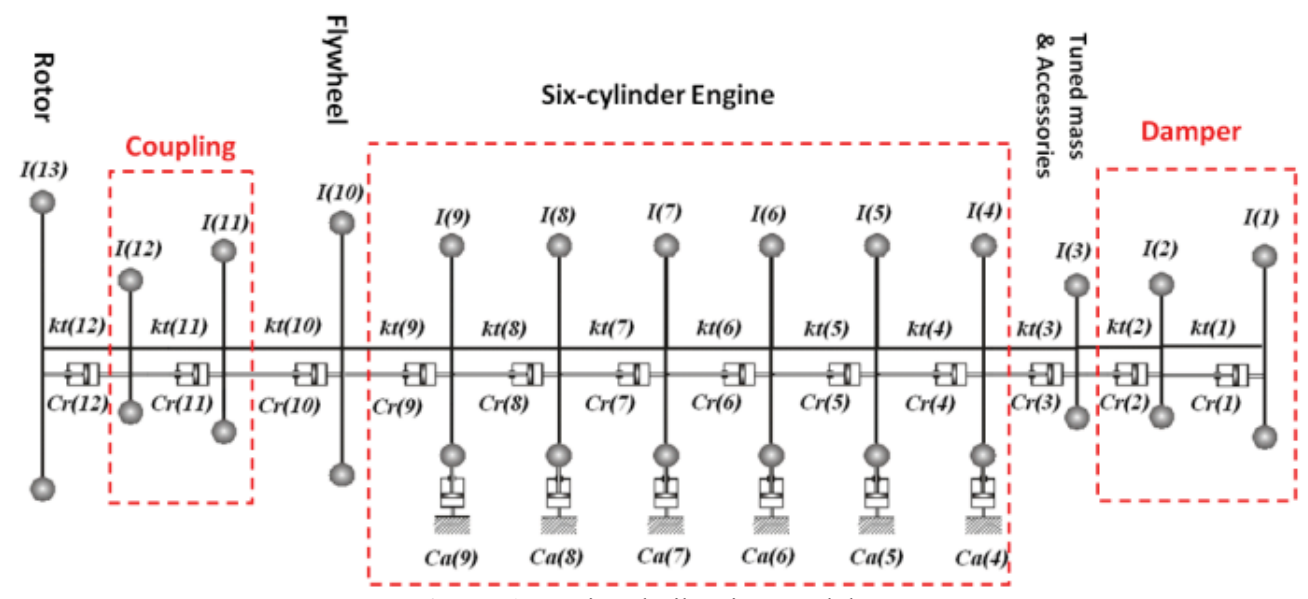

Figure 1.Torsional vibration model

\section{Excitation and boundary condition}

In the torsional vibration system, the excitation per cylinder is usually loaded by a tangential pressure and inertia components as described in B.I.C.E.R.A [2]. Here, gas forces at different speeds, as shown in Figure 2, were used for excitation in both software applied on the pistons. The gas pressures at different engine speeds were measured using high temperature piezoelectric pressure sensors for three cylinders. The engine operation speed is in the range of $600 \mathrm{rpm}$ (Idle) to $1800 \mathrm{rpm}$ (maximum rated speed). Considering $15 \%$ overspeed for the engine, the engine speed may increase up to $2070 \mathrm{rpm}$. Inertia loads are also calculated based on the model mass and the inertia properties by the software.

As mentioned before, the first model was created based on the Multi-Body Dynamic in $\mathrm{ADAMS}^{\circledR}$. Standard interface was utilized in $\mathrm{ADAMS}^{\circledR} /$ Engine software to generate dynamic model of cranktrain. Joints between each component were generated automatically using Standard Interface. As mentioned before, in ADAMS ${ }^{\mathbb{R}}$, the crankshaft is considered as torsional-flexible (not full flexible) and the analysis is done based on the Multi-Body Dynamic. The boundary conditions consisting gas forces and engine mountings were applied to the model. In addition, a constant rotation speed was applied to the driven machinery. The coupling and the rotor were attached to the flywheel end of the crankshaft in $\mathrm{ADAMS}^{\circledR}$.

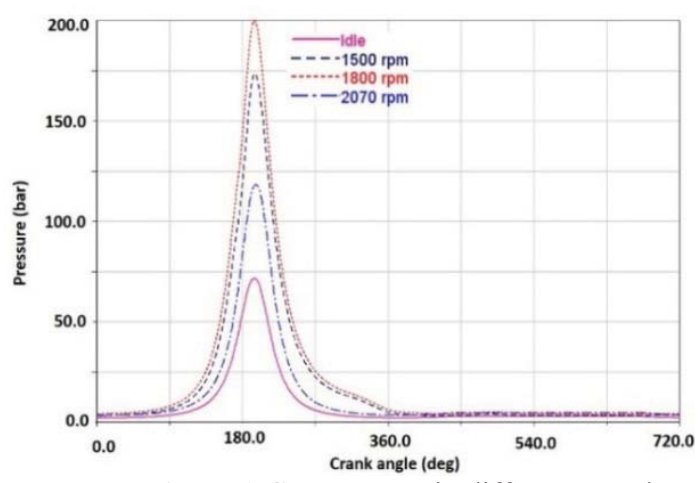

Figure 2.Gas pressure in different speed
The other model was created in AVL Excite ${ }^{\circledR}$ which is very similar to ADAMS $^{\circledR}$ model, but the method of solution is based on the Extended (include exciting) Holzer Method as mentioned before, (AVL Theory Manual). The natural frequency and mode shapes of a multi-mass lumped parameter system can be determined by this iteration method as devised by Holzer. It's applicable to forced, free, damped, undamped and semi-definite systems as well. A typical multi-rotor system can be considered as shown in Figure 3.

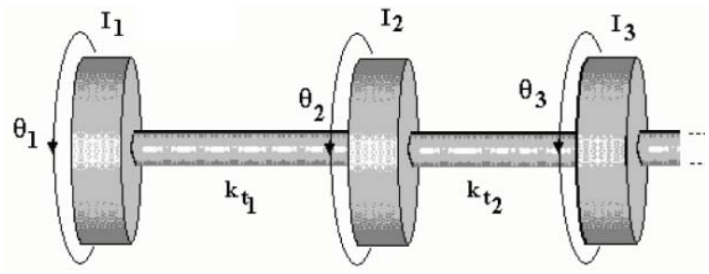

Figure 3. Multiple inertia system

For any number of discs this may be generalized as $\sum I \omega^{2} \theta=0$. Holzer's method of solution proposes that be assumed any value of $\omega$ and made $\theta_{1}=1$ and calculated all the other deflections. Since $\sum I \omega^{2} \theta=0$ must be satisfied, then the last $\mathrm{T}$ must be zero when the oscillation is free. The problem is to find the values of $\omega$ that make this so and these are the natural frequencies of the system. If a computer program is used, it is relatively simple to evaluate the displacements and the torque for all valued of $\omega$.

\section{Problem}

The first step is the initial selection of tuned mass inertia which is usually done based on the engine manufacturer experience. In the following, the design variable and purposes for the problem are discussed. 


\section{Design variable; Tuned mass inertia}

It is possible to reduce the torsional vibration amplitude, where a resonance peak occurs at the running speed of an engine, using (B.I.C.E.R.A, 1958). This mass can affect significantly the torsional vibration system. The effect of this technique (adding a tuned disk to the crankshaft free end) proved a significant reduction in the nominal alternating torques, as shown in Figure 4, which decreases the crankshaft stresses. Trial numbers are defined based on Table 1 .

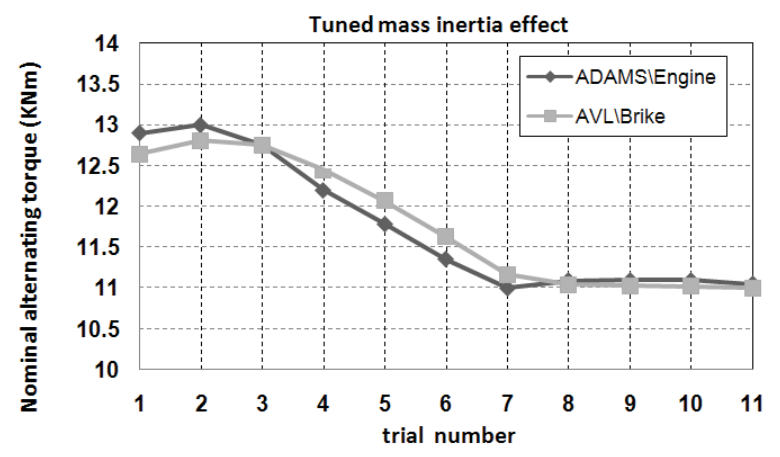

Figure 4. Effect of tuned mass inertia on nominal alternating torque in critical section of crankshaft

\section{Purposes}

The first important factor which should be considered in an engine torsional system design is the torsional torques applied to the crankshaft which directly affects the crankshaft high cycle fatigue safety factor. This safety factor is defined based on the crankshaft life assessment methods which have been standardised by classification societies through IACS (International Association of Classification societies [15]) namely URM53.The sufficient dimensioning of a crankshaft is confirmed by a comparison of the equivalent alternating stress and the fatigue strength. This comparison has to be carried out for the crankpin fillet, the journal fillet, the outlet of crankpin oil bore. Therefore, the typical areas of the interest for a crankshaft are the journal pin fillet, crank pin fillet and oil holes. These are the main three regions where stress concentration is relatively high because the cross-section changes at these points. Where a crankshaft design involves the use of surface treated fillets, or when fatigue parameter influences are tested, or when working stresses are measured, the relevant documents with calculations/analysis are to be submitted to Classification Societies in order to demonstrate equivalence

Table to the Rules. These Rules apply only to solid-forged and semi-built crankshafts of forged or cast steel, with one crank throw between main bearings. Calculation of crankshaft strength consists initially in determining the nominal alternating bending and nominal alternating torsional stresses which, multiplied by the appropriate stress concentration factors, result in an equivalent alternating stress. This equivalent alternating stress is then compared with the fatigue strength of the selected crankshaft material. This comparison will show whether or not the crankshaft concerned is dimensioned adequately.

In the current case, the crank pin fillet and oil holes are critical sections. Using UR-M53 classification rule, the levels of the high cycle fatigue safety factor in the crank pin fillet, journal pin fillet and oil holes are derived.

\section{Results}

Tuned mass inertia is changed in the range of $\pm 100 \%$ around the initial values specified in the parenthesises. The values for the engine tuned mass inertia for the investigation are shown in Table 2. Effects of the tuned mass on the torque range and the torque average have been shown in Figure $5 \mathrm{a}$ and $\mathrm{b}$, respectively. It is clear that it has significant effect on them. Also these effects on the crankshaft safety factors at crankpin fillet and crankpin oil hole are shown in Figure $5 \mathrm{c}$ and $\mathrm{d}$, respectively. It is obvious from these figures that the critical zone in this case is crankpin oil hole. The red horizontal line as a criterion distinguishes the safe running, obtained by high cycle fatigue safety factor upper than 1.15.It can be seen that the influence of tuned mass on increasing the life of the crankshaft is really significant. The effect of the tuned mass on the other parameters such as the damper power dissipation and the vibration amplitude at crankshaft free end are respectively presented in Figure $5 \mathrm{e}$ and $\mathrm{f}$. This effect on the damper heat load is considerable while it doesn't have an important effect on the vibration amplitude at the crankshaft free end.

As described before, the selection process of optimum tunned damper is started with selection of the initial values for the torsional system properties. The parameters listed in Table 2 are studied to optimise the torsional system properties. The mentioned parameter is changed in the range of $\pm 100 \%$ around the initial values specified in the parenthesises, as shown in

Table 1. Variation interval (initial values are specified in parenthesises)

\begin{tabular}{ccccccc}
\hline $\begin{array}{c}\text { Trial } \\
\text { number }\end{array}$ & $\begin{array}{c}\text { Tuned mass } \\
\text { inertia } \\
(\mathrm{kgm} 2)\end{array}$ & $\begin{array}{c}\text { Flywheel } \\
\text { inertia } \\
(\mathrm{kgm} 2)\end{array}$ & $\begin{array}{c}\text { Damper } \\
\text { stiffness } \\
(\mathrm{MNm} / \mathrm{rad})\end{array}$ & $\begin{array}{c}\text { Damper inertia- } \\
\text { outer and inner ring } \\
(\mathrm{kgm} 2)\end{array}$ & $\begin{array}{c}\text { Damper } \\
\text { damping } \\
(\mathrm{Nms} / \mathrm{rad})\end{array}$ & $\begin{array}{c}\text { Coupling } \\
\text { damping } \\
(\mathrm{Nms} / \mathrm{rad})\end{array}$ \\
\hline $\mathbf{1}$ & 0 & & & $\begin{array}{c}\text { Coupling } \\
\text { stiffness } \\
(\mathrm{MNm} / \mathrm{rad})\end{array}$ \\
$\mathbf{3}$ & 0.1 & & & \\
\hline
\end{tabular}




\begin{tabular}{cccccccc}
\hline $\mathbf{4}$ & 0.3 & & & & & & \\
$\mathbf{5}$ & 0.4 & $(4.7600)$ & $(0.43)$ & $(.0883-0.0591)$ & $(150.000)$ & $(19.27)$ & $(0.0230)$ \\
$\mathbf{6}$ & $(0.5)$ & & & & \\
$\mathbf{7}$ & 0.6 & & & & \\
$\mathbf{8}$ & 0.7 & & & & \\
$\mathbf{9}$ & 0.8 & & & & \\
$\mathbf{1 0}$ & 0.9 & & & & \\
$\mathbf{1 1}$ & 1 & & & & \\
\hline
\end{tabular}

Table 2. Parameterand purposes for the problem

\begin{tabular}{l|l}
\hline Design variables & Objectives \\
\hline Tuned mass inertia (if available) & Crankshaft torsional torque amplitude \\
& Crankshaft vibration amplitudes \\
& Damper power dissipation \\
\hline
\end{tabular}

The effects of different torsional system properties were presented in Table 3 It should be mentioned that however the two simulation packages (ADAMS ${ }^{\circledR}$ and AVL $($ ) have two different methods, but their results have close agreement. This shows the acceptability of the results of each software package for doing a good selection. The main important purpose in this problem is the crankshaft fatigue life which is mainly depends on the nominal alternating torque and mean torque. Therefore, one of the influential parameters is tuned mass inertia. As shown in Figure 5, the current value for tuned mass (trial number 6) is appropriate as objective and no more iteration is needed. According to Table 3, tunned mass inertia has strong effect on damper power dissipation, nominal alternating torque, mean torque and consequently on crank pin fillet SF and crankpin oil hole SF. It also has a medium effect on free end vibration angle.

The next step is to check the effect of different values of the tuned mass inertia with considering a different damper (new inertia and stiffness values) and to investigate the objectives due to change of these parameters. As shown in Figure $6 \mathrm{a}$ and $\mathrm{b}$, a change in inertia level of tuned mass depends on the damper used in the TV system. Therefore it is concluded that the tuned mass in a TV system must be selected while associating with the TV damper, called tuned damper. Therefore, it can be concluded that this part (tuned mass or tuned disk) while significantly affecting the behaviour of the torsion system, also depends on the selection of damper.

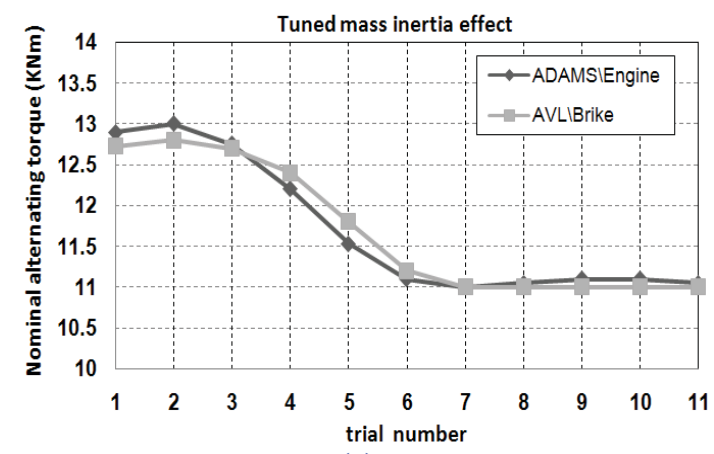

(a)

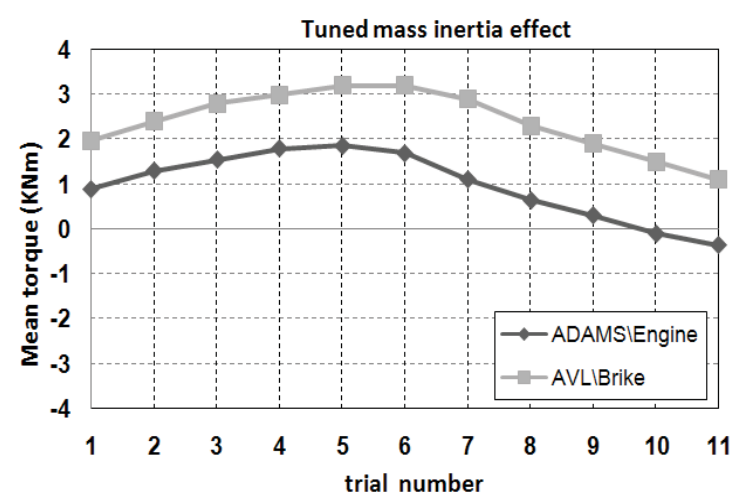

(b)

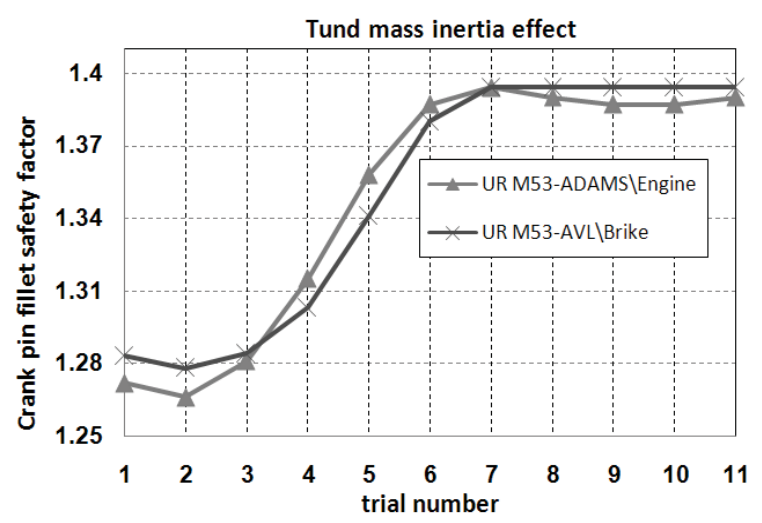

(c) 


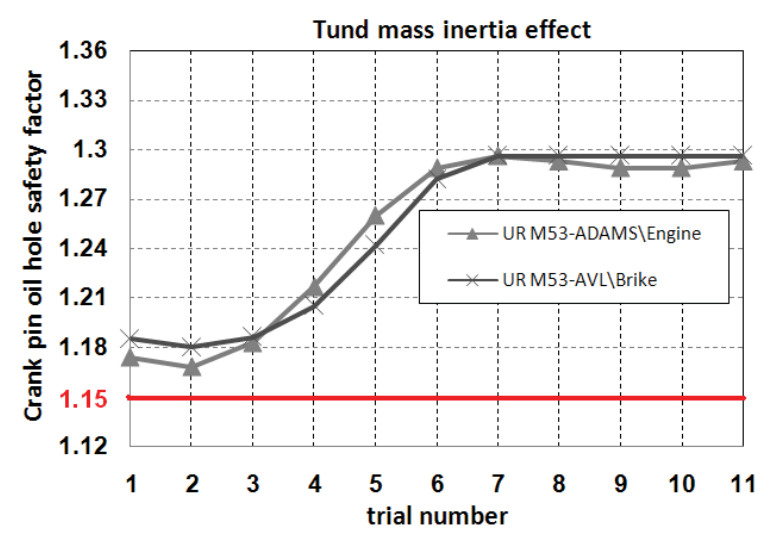

(d)

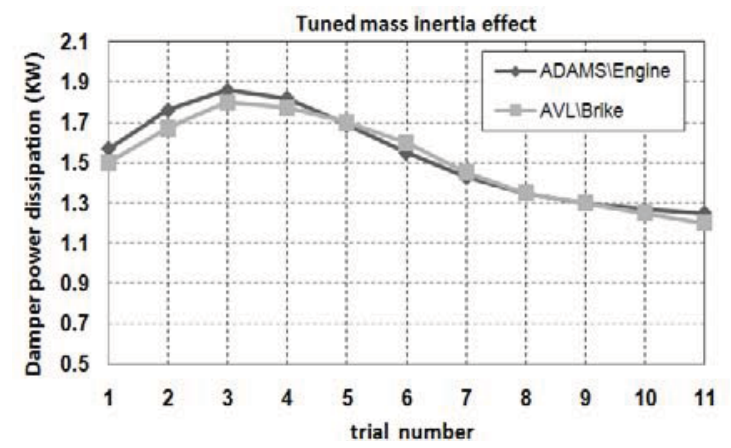

(e)

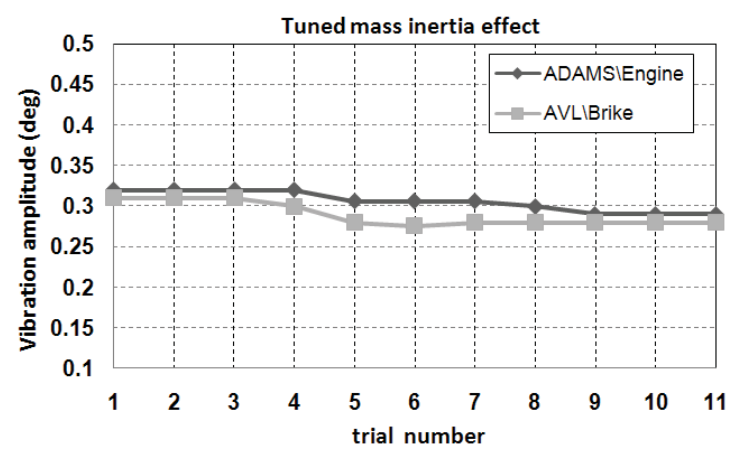

(f)
Figure 5. In critical section of crankshaft: (a) Effect of tuned mass inertia on nominal alternating torque, (b) Effect of tuned mass inertia on mean torque, (c) Effect of tuned mass inertia on crankpin fillet safety factor, (d) Effect of tuned mass inertia on crankpin oil hole safety factor, (e) Effect of tuned mass inertia on damper power dissipation, (f) Effect of tuned mass inertia on crankshaft free end vibration amplitude

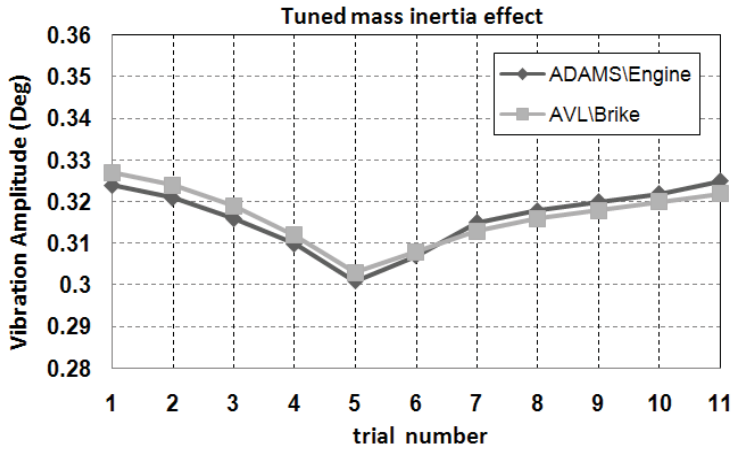

(a)

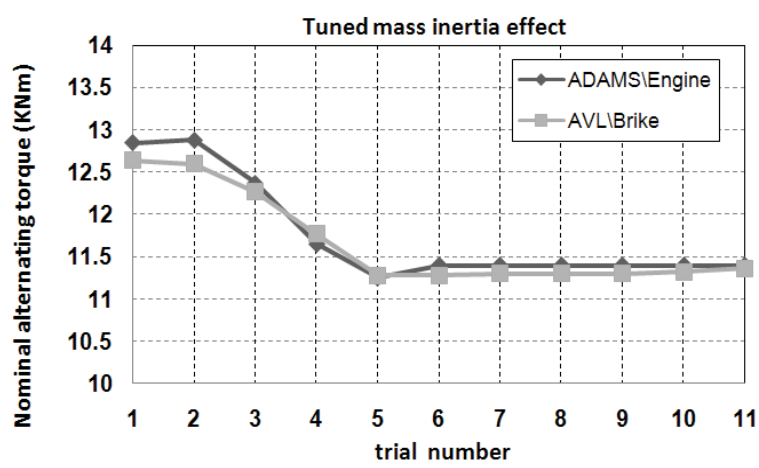

(b)

Figure 6. (a) Effect of tuned mass inertia on crankshaft free end vibration amplitude, (b) Effect of tuned mass inertia on nominal alternating torque in critical section of crankshaft

Table 3. Effect of parameters

\begin{tabular}{|c|c|c|c|c|c|}
\hline $\begin{array}{l}\text { Free end } \\
\text { angle } \\
\text { (deg) }\end{array}$ & $\begin{array}{l}\text { damper power } \\
\text { dissipation } \\
(\mathrm{KW})\end{array}$ & $\begin{array}{l}\text { Nominal } \\
\text { alternating } \\
\text { torque } \\
(\mathrm{KNm})\end{array}$ & $\begin{array}{l}\text { Mean torque } \\
(\mathrm{KNm})\end{array}$ & $\begin{array}{c}\text { Crank pin } \\
\text { fillet SF }\end{array}$ & $\begin{array}{l}\text { Crank pin } \\
\text { oil hole SF }\end{array}$ \\
\hline
\end{tabular}

OVERALL

\begin{tabular}{ccccccccc}
\hline Tuned mass inertia & $\mathrm{M}^{*}$ & $\mathrm{H}^{* *}$ & $\mathrm{H}$ & $\mathrm{H}$ & $\mathrm{H}$ & $\mathrm{H}$ & $\mathrm{H}$ \\
\hline Note: $*$ Medium, $* *$ High & & &
\end{tabular}

\section{Conclusion}

To study the effect of the tuned mass of a heavy-duty inline engine on TV system design criteria, two useful commercial software were employed. The first simulation was carried out using $\mathrm{ADAMS}^{\circledR} /$ Engine, and the next one was carried out by $\mathrm{AVL}^{\circledR} /$ Designer software. In fact, the two different methods, implemented by the two mentioned different software packages, have been used in order to study the torsional vibration system. They are different in method however, both have close agreement in the results which confirms the correctness of the simulation and shows the reliability of the results. 
It is concluded that the tuned mass can change the torsional vibration behaviour of the engine, therefore adding this part to the crankshaft free end can cause to improve the torsional parameters and consequently improve the crankshaft life (high cycle fatigue safety factor in critical sections of crankshaft). The results showed that change in inertia level of the tuned mass depends on the damper used in the TV system. Therefore the tuned mass in a TV system must be selected associated with the TV damper, called tuned damper. Thus, it is concluded that this part (tuned mass or tuned disk) while significantly affecting the behaviour of the torsion system, also depends on the selection of damper.

\section{Funding}

This research received no specific grant from any funding agency in the public, commercial, or not-forprofit sectors.

\section{References}

[1] Mendes, A. S., Meirelles, P. S., and Zampieri, D. E., "Analysis of torsional vibration in internal combustion engines: modelling and experimental validation," Proceedings of the Institution of Mechanical Engineers, Part K: Journal of Multi-body Dynamics, 222(2):pp. 155-178, 2008.

[2] Nestorides, E. J., ed. A handbook on torsional vibration. Cambridge University Press, 1958.

[3] Wilson, WK.,Practical solution of torsional vibration problems: with examples from marine, electrical, aeronautical, and automobile engineering practice.,Chapman \& Hall; Vol. 2, 1956.

[4] Hafner, KE. and Maass, H.,Theorie der Triebwerksschwingungen der Brennkraft maschine, WienNew York;Vol. 3, 1984.

[5] Chen, S.K., and Chang, T.,"Crankshaft torsional and damping simulation - an update and correlation with test results," SAE transactions,pp. 964-985, 1986.
[6] Larmi, M. "Torsional vibration calculation and engine damping," Proceedings of international congress on combustion engines (CIMAC),pp. 96-105, 1988.

[7] Boysal, A., and Rahnejat, H., "Torsional vibration analysis of a multi-body single cylinder internal combustion engine model," Applied Mathematical Modelling, 21(8): pp. 481493, 1997.

[8] Ma, ZD. and Perkins, NC.,"An efficient multibody dynamics model for internal combustion engine systems." Multibody system dynamics, 10(4): pp. 363-391, 2003.

[9] Desbazeille, M., Randall, RB., Guillet, F., El Badaoui, M. and Hoisnard, C. "Model-based diagnosis of large diesel engines based on angular speed variations of the crankshaft," Mechanical Systems and Signal Processing, 24(5): pp. 1529-1541, 2010.

[10]Han, HS., Lee, KH. and Park, SH. "Parametric study to identify the cause of high torsional vibration of the propulsion shaft in the ship," Engineering Failure Analysis, 59(1), pp. 334-346, 2016.

[11]Guo, Y., Li, W., Yu, S., Han, X., Yuan, Y., Wang, Z. and Ma, X.,"Diesel engine torsional vibration control coupling with speed control system," Mechanical Systems and Signal Processing, 94 (1): pp. 1-13, 2017.

[12]MSC ADAMS. Documentation and help, Using Adams/Engine, 2005.

[13]AVL LIST GmbH. AVL Excite Designer, Theory Manual Version 7.0.3, October 2007.

[14]Milasinovic, A., Filipovic, I. and Hribernik, A. "Contribution to the definition of the torsional stiffness of the crankshaft of a diesel engine used in heavy-duty vehicles." Proceedings of the Institution of Mechanical Engineers, Part D: Journal of Automobile Engineering, 223(7): pp. 921-930, 2009.

[15]IACS UR M53, International Association of Classification Societies (IACS) Unified Rules UR-M53 for the calculation of Crankshaft Design Strength Assessment for I.C. Engines 1986 (Rev.1, Dec 2004). 